73rd Conference of the Italian Thermal Machines Engineering Association (ATI 2018), 12-14 September 2018, Pisa, Italy

\title{
Refugee camps as an opportunity for promoting alternative development strategies based on carbon credits
}

\author{
Mattia Manni ${ }^{\mathrm{a}, \mathrm{b}, *}$, Flavia Ragnaccic ${ }^{\mathrm{c}}$, Marco Filippucci ${ }^{\mathrm{c}}$, Valentina Coccia ${ }^{\mathrm{a}, \mathrm{b}}$, Fabio \\ Bianconi $^{\mathrm{c}}$, Franco Cotana ${ }^{\mathrm{a}, \mathrm{b}}$, Alessandro Petrozzi ${ }^{\mathrm{a}}$ \\ ${ }^{a}$ Ciriaf-Research Center on Environment and Pollution "M. Felli", Via G. Duranti, 06125, Perugia \\ ${ }^{b}$ Department of Engineering, University of Perugia, Via G. Duranti, 06125, Perugia \\ ${ }^{c}$ Department of Civil and Environmental Engineering, University of Perugia, Via G. Duranti, 06125, Perugia
}

\begin{abstract}
The difficult social issues faced by non-governmental organizations regarding planning, management, and evolution of the refugee camps led to evaluating alternative development strategies. Indeed, innovative technologies could be promoted for sustainably enhancing local economy. The present model suggests the exploitation of highalbedo materials to generate cool oases in hot climate contexts. The benefits derived by this proposal were investigated by simulating the application of high-albedo devices on shelters in Zaatari, then the avoided carbon emissions were quantified, and several scenarios were discussed. In the framework of the Emissions Trading System, the carbon credits, which can be obtained and sold by contributing to the global warming mitigation process, are estimated to be

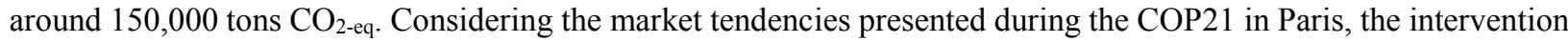
is demonstrated to be sustainable in economic and environmental terms. The payback period is estimated in 3 years in the most reliable scenario. The work presents the main results of a wider research that also included consideration about the urban planning of the camps.
\end{abstract}

(C) 2018 The Authors. Published by Elsevier Ltd.

This is an open access article under the CC BY-NC-ND license (https://creativecommons.org/licenses/by-nc-nd/4.0/)

Selection and peer-review under responsibility of the scientific committee of the 73rd Conference of the Italian Thermal Machines Engineering Association (ATI 2018).

\footnotetext{
* Corresponding author. Tel.: +39-075-585-3806; fax: +39-075-515-3321.

E-mail address: manni@crbnet.it
} 
Keywords: Albedo; Sustainable development; Refugee camp; Emission Trading System.

\section{Introduction}

Refugee camps are usually financed through funds coming from governmental authorities or humanitarian associations, but in most of the cases they are not enough for satisfying the primary needs of the refugees. According to the research carried out by Bartolini [1], one of the bigger refugee camps, the one in Zaatari, has an operational cost - only for guaranteeing refugees food and potable water - of around 500,000 dollars per day. Thus, the necessity of developing strategies to attract private and more consistent funds, is becoming fundamental. Furthermore, the guaranty of acceptable life conditions to refugees is not the only issue faced by local governance authorities. The camps themselves are living organisms, continuously changing, evolving, and adapting to their inhabitants' needs. Hence, integrating housing refurbishment and camp planning with the development of strategies to produce economic benefits, would represent an important step on the camps' growing process. Indeed, the population living on refugee camps is continuously raising because of the natural catastrophes, conflicts, and similar emergencies. Nowadays, around 6 million of persons are forced to live in one among the 450 refugee camps which are managed by United Nations High Commissioner for Refugee (UNHCR) and United Nations Relief and Works Agency (UNRWA), although Amnesty International states that this valuation could be 600 considering unofficial camps too.

The present work is part of a wider research that is described on the thesis carried out by Ragnacci, entitled "Albedo for Zaatari, Albedo and requalification of Zaatari refugee camp" [2]. It aims to propose a developing strategy for refugee camps which could permit them to be as much independent as possible from the public funds by investing on technologies such as high reflective (HR) coatings, for avoiding carbon emissions as well as improving population's comfort. Indeed, the avoided emissions have an economic value and they can be sold through the Emission Trading System (ETS).

\subsection{High-reflective materials for mitigating global warming effect}

Nowadays more than the $50 \%$ of the global population - around 3.9 billion - lives in urban areas; nevertheless, this value is expected to grow until $66 \%$ - around 6.6 billion - by 2050 [3]. It implies the growing of cities' extension and the consequent worsening of the Urban Heat Island (UHI) effect [4]. The raising of the urban temperature along with the greater heat gains through buildings' envelopes lead to an increment of the energy requirements for cooling. Furthermore, other effects, which are not secondary at all, are related to the urban environment such as a reduced canyon ventilation and harder pollutant dispersion concerning people's health and air quality [5].

The magnitude of UHI depends on latitude, and on a wide range of factors which can be clustered in two main categories: architectural-urbanistic and environmental [6]. But it is not the only accepted classification, several ones have been proposed during the last decades. Oke [5] identified five categories: anthropogenic heat (i), air pollution (ii), extension of waterproof surfaces (iii), thermal properties (iv) and surfaces geometry (v). Similarly, Akbari [7] demonstrates how urban sprawl phenomenon and the consequent reduction of green areas could be considered as the main causes which lead to the heightening of the anthropogenic heat.

Since UHI effect is related to the solar energy absorbed by urban blocks and slowly released by night, the most the city is extended and complex, the hardest is dissipating the stored heat. Thus, the main strategies proposed to mitigate that phenomenon work on the reduction of the collected solar energy by increasing envelopes' reflection (cool materials) and evapotranspiration (green areas and permeable surfaces) [7]. In that regards, the studies carried out by Taha [8] evaluate several areas at different latitudes characterized by diverse levels of albedo, evapotranspiration and anthropogenic heat above cities. The results confirmed how cool materials could generate lighter convective heat flows, by showing as samples the architectures from North African urbanized areas where the albedo equals 0.30-0.45. Several guidelines and best practices, such as New York High Performance Infrastructure Guidelines [9] and Philadelphia High Performance Building Renovation Guidelines [10], confirmed the importance of high albedo 
coatings for roofs and floors to mitigate the urban overwarming. Such a practice has been applied for years in villages located in extremely hot contexts such as the Mediterranean area. Applying on building a painting with brilliant colors allows to increase the reflectivity, while lowering indoor temperature. In addition to that, some retroreflective (RR) enhanced coatings permit to send the solar radiation back to the source maintaining constant its wavelength. In this way the worsening of the greenhouse effect is avoided, and the urban temperature is reduced.

The Albedo is the portion of solar energy - shortwave radiation - reflected by the Earth towards the space, and it is commonly employed for describing the reflective properties of a surface. The effectiveness of technologies regarding Albedo control have been largely investigated by Ciriaf - Research Centre on Environment and Pollution "M. Felli" and approved by the scientific community [11]. To better understand how HR materials could be one of the main strategies to mitigate the global warming and offset carbon emissions, it must be introduced the Earth Thermal Balance (ETB). It is a phenomenon that involves solar radiation, chemical composition of the atmosphere, as well as ground and water properties. The ETB permits to understand how incoming solar radiation is absorbed, reflected and transmitted. According to that, a high albedo value allows to reflect most of the radiation unaltering the wavelength. In conclusion, this process allows to control the greenhouse effect and estimating the quantity of carbon emissions avoided with HR coatings.

This approach has been already investigated on few case studies in the Mediterranean zone during the research activities conducted by Ciriaf-CRB of Perugia. A HR coating was applied to the $1,200 \mathrm{~m}^{2}$ wide petrol station's rooftop in Firenzuola (Italy) which guarantees to offset up to $100 \mathrm{tCO}_{2 \text {-eq }}-$ equal to one million cars' emissions through the year. Similarly, the ABCD Project, that was developed in Tunisi, tested the efficiency of high Albedo surfaces at lower

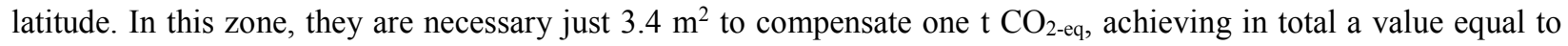
$30,000 \mathrm{t} \mathrm{CO}_{2 \text {-eq. }}$

All those applications represent part of the background of the "Albedo for Africa" project [12-14] which aims to promote high Albedo enhanced technologies as a strategy to mitigate the global warming and to promote the Sustainable Development Goals (SDG) implementation, promoting an economy model able to generate job opportunities and social development in African countries. The objective of the proposal is to develop 50,000 "cool settlements" in Sub-Saharan area, which could offset 9 billion tons of $\mathrm{CO}_{2}(30 \%$ of the global emissions). The main goals of the project are (a) self-sustainability through the incorporation of albedo technologies within the ETS [15], (b) enrolling local workers, (c) developing circular economy-based villages which promote $\mathrm{CO}_{2}$ compensation through HR technologies [16-18], (d) using satellite system for having an accurate value of the avoided emissions [19-20]. The typical village designed for this proposal can host up to 1,500 inhabitants and it is characterized by an extension of 40 ha. The amount of $\mathrm{CO}_{2}$ offsets by one village should be around $80,000 \mathrm{tCO}_{2 \text {-eq }}$ per year.

\subsection{European Emission Trading System}

The Emission Trading System (ETS) is a European recognized method, initially proposed on the Kyoto Protocol document [21], for selling and buying emission credits in order to achieve a reduction of the carbon emissions released by the most impacting sectors. The European Directive 2003/87/CE [22] described such a "cap and trade" methodology: it proposes the maximum pollution levels which can be reached for each activity (cap), while defining the principles which regulate the trading system of carbon credits for offsetting the exceeding emissions (trade). According to that, the persons in charge of the plants' management could choose among different compensation strategies such as investing on renewable energy sources or buying credits depending on the business plan [23]. A similar approach has been already applied by FIFA association since 2006, for significantly reducing the environmental impact of their main events as the FIFA World Cup [24]. Nevertheless, the "cap and trade" system has shown some limits which have been discussed in France during the 21 st Conference of Parties (COP21). Among those, the $\mathrm{CO}_{2}$ cost seems to be the main issue to be faced. In fact, the actual price for acquiring one ton of carbon emission (5.00 $€ / \mathrm{tCO} 2-\mathrm{eq})$ is considered too low for promoting the energy transition towards technologies with a sustainable impact. The economic crisis generates a surplus of available credits with the consequent drop of the price. The investigated scenario which should solve the issue and improve the efficiency of the "cap and trade" system is based on the definition of a "price corridor" oriented to the gradual increment of the carbon credits' cost. In that regards, the $5.00 € / \mathrm{tCO} 2$-eq are supposed to raise up to $20.00-30.00 € / \mathrm{tCO} 2$-eq in 2020 , and then constantly growing with a rate ranging between $5 \%$ and $10 \%$ in order to achieve $50.00 € / \mathrm{tCO} 2$-eq in 2030 . 


\begin{tabular}{|ll|}
\hline Nomenclature \\
UNHCR & United Nations High Commissioner for Refugee \\
UNRWA & United Nations Relief and Works Agency \\
HR & High Reflective \\
ETS & Emission Trading System \\
RR & Retroreflective \\
ETB & Earth Thermal Balance \\
SDG & Sustainable Development Goals \\
RES & Renewable Energy Sources \\
\hline
\end{tabular}

\section{Method}

\subsection{Case study: Zaatari refugee camp}

Refugee camps are usually located close to the national borders in order to reduce as much as possible the transport distances and facilitate the repatriation process. In compliance to those guidelines [25], Zaatari refugee camp has been settled next to the Jordanian northern frontier, not far from Syria (around $15 \mathrm{~km}$ ). The first camp's elements were realized on July 2012 occupying a total extension equal to $5.2 \mathrm{~km}^{2}$. It became the symbol of the displacement of a high number of Syrian people within the Middle East after the Syrian Civil War had been broken out. In few years the camp, which initially was only a chaotic group of tents put together in less than ten days, has become almost a real city that nowadays is the third biggest in Jordan. Its population is around 80,000 inhabitants (UNHCR online database, updated on $7^{\text {th }}$ April 2018), living in 12 districts [26]. Anyway, the actual refugees' number is quite far from the maximum achieved on April 2013, when the hosted up to 200.,000 persons [27]. Consequently, as the population had been varying, Zaatari changed its shape by adapting to the refugees' needs, climate conditions and cultural background. The refugees are the main urban planners and designers of the settlement layout: since the shelters are very light and easy to move, they usually bring their houses where they prefer.

The Jordan region, where the camp is located, is in a desertic zone, characterized by extremely hot climate conditions and a significant temperature's variation between summer and winter. Stating that, the building typologies which are frequently employed on the refugee camps do not seem to be able to guarantee an adequate comfort level for their inhabitants. It leads most of the refugees to the realization of self-made shading systems, realized with clothes, metal sheets, ropes, and stones found on the camp. Thus, the present work aims to propose a rapid and effective solution to this issue in order to enhance directly - indoor comfort conditions' improvement - and indirectly exploitation of the carbon credits' trade for increasing the available funds - the refugees' life quality. The proposal consists of a modular shading system with high reflective properties, that could also guarantee an adequate ventilation and privacy, as well as assembling ease and replicability. Furthermore, the high-albedo enhanced intervention would permit to reduce the overwarming of the camp's area, and in general the global warming.

From an economic point of view, the shading system aims to be a low-cost solution, made by recycled environmentfriendly materials. The proposal consists also in reusing waste from the old tents which are not used anymore, as well as tarp and ropes. In case it would be necessary buying all the materials, the total cost will be around $130 €$ per shelter. 

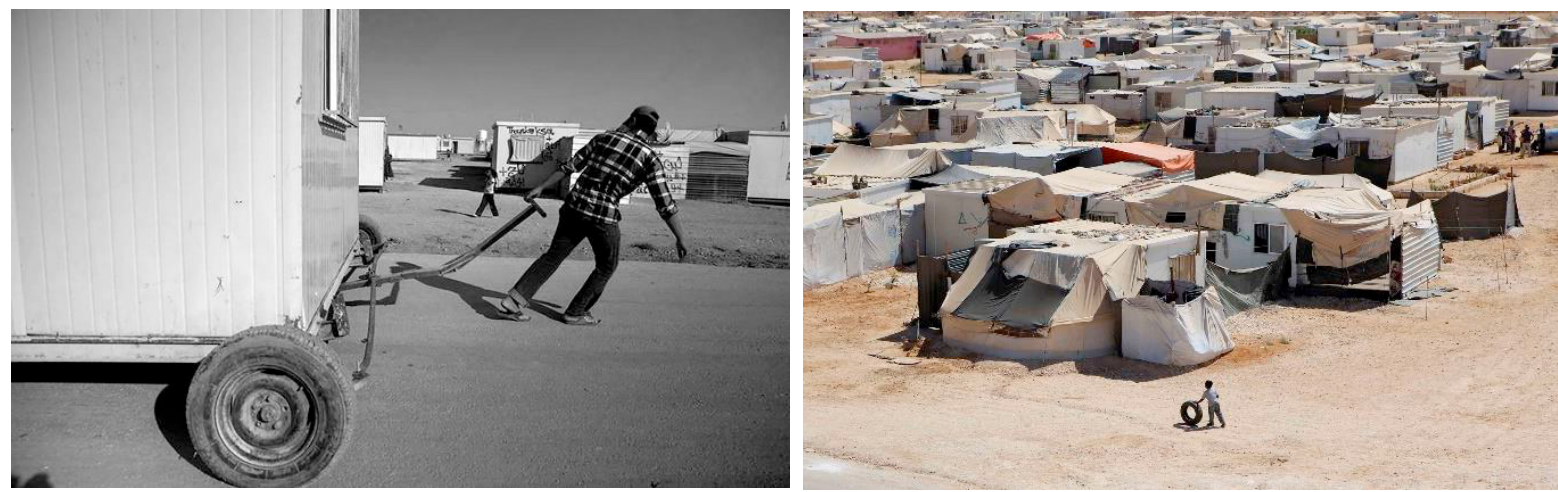

Fig.1. Details of Zaatari refugee camp's evolution (contents from: presidentsmedals.com, and mimesis-scenari.it).

\subsection{Numerical model for Albedo calculation}

Once the costs of the interventions were estimated, the preliminary business plan has been defined to demonstrate the economic feasibility of the proposal. The starting costs were calculated considering that the application of the shading system on the shelters would be conducted at the same moment on the whole camp, and the operational costs - mainly related to the painting maintenance - were estimated as the one percent of the initial investment. Then, the payback period has been evaluated basing on the three carbon credits' values, which range from $5.00 € / \mathrm{tCO}_{2 \text {-eq }}($ actual scenario) to $50.00 € / \mathrm{tCO}_{2 \text {-eq }}$ (until 2030), proposed by the French experts at the COP21 in Paris.

The calculation of the carbon credits which could be produced in the refugee camp through the high albedo devices, was conducted by employing the analytical model developed by Ciriaf of Perugia. In fact, the high reflective painting permits to reflect towards the atmosphere the incident solar radiation without altering the wavelength. The process enables the reduction of the energy stored on the Earth which contributes to the worsening of the global warming effect. The study carried out by Akbari et al. [28] demonstrated that $16 \mathrm{~m}^{2}$ of cool roof allowed to counterbalance up to one $\mathrm{tCO}_{2 \text {-eq. }}$. Furthermore, according to the Spatially Explicit Global Climate, the increment of the unitary surface's albedo by 0.01 permits to compensate an amount of carbon emissions varying from $6.5 \mathrm{tCO}_{2 \text {-eq }}$ to $7.5 \mathrm{tCO}_{2 \text {-eq }}$ [29]. All those considerations have been included on the numerical model based on the equation (1) for estimating the amount

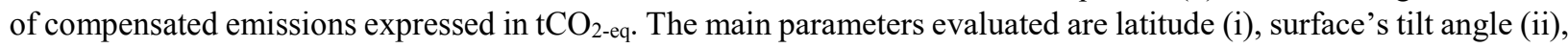
azimuthal angle (iii), surface's albedo (iv), surface's geometry (v).

$$
\begin{array}{ll}
\text { tons } & \mathrm{CO}_{2 \text {-eq }}=f(1, \alpha, \theta, \mathrm{S}, \mathrm{A}, \tau, \mathrm{w}) \\
1 & \text { latitude } \\
\alpha & \text { surface tilt angle } \\
\theta & \text { azimuthal angle } \\
\mathrm{S} & \text { surface's extension } \\
\mathrm{A} & \text { surface's albedo } \\
\tau & \text { exposure time } \\
\mathrm{w} & \text { weather conditions }
\end{array}
$$

Then, the high reflective surface's extension has been estimated by the specific function in Revit software, which was employed for modelling the camp's layout using multicategories abacus. The calculated value has been used for quantifying both the costs (initial and operational) and the earned carbon credits. 


\section{Results and discussion}

On the first stage of the workflow, the square meters necessary for compensating one ton of $\mathrm{CO}_{2}$ released in atmosphere were calculated by applying the Ciriaf analytical model, which estimated this quantity equal to $7.35 \mathrm{~m}^{2}$. Then, the shelters' area was calculated in Revit software environment $\left(900,000 \mathrm{~m}^{2}\right)$, although this value has been later increased by $20 \%$, achieving the $1,075,000 \mathrm{~m}^{2}$ since the shading system is larger than the single residential unit. Considering these information, the coating such a wide surface with high Albedo paintings would allow to compensate up to 150,000 tons of carbon emissions per year, which could be sold as carbon credits for balancing the installation and operational costs. The impact of the Zaatari's HR surfaces on the global carbon emissions is far from being significant since it represents only the $0.1 \%$ of the tons of carbon dioxide released in atmosphere during 2015 according to UNSD report, around $27,000,000 \mathrm{KtCO}_{2 \text {-eq }}$ [30]. Nevertheless, it must be considered that the refugee camp is only $5.2 \mathrm{~km}^{2}$ and one of the research goals is demonstrating the replicability of the intervention in other similar contexts with low costs. According to Amnesty International's assessments there are 450 official camps, set up in the last years, managed by UNHCR and UNRWA, which arise to 600 considering the unofficial ones. These numbers show the intensity of the phenomenon and the opportunity to replicate the same project in a lot of other camps. The economic evaluation conducted regarding the proposed technology demonstrated how its cost per shelter is affordable - less than $130 €$ - considering the consequent improvement of the indoor comfort level. On the other hand, the application to the whole Zaatari refugee camp would have a total cost of $6 \mathrm{M} €$. The Emission Trading System represents the chosen tool for obtaining an economic profit from sustainable interventions and best practices like the proposed one. According to the methodology discussed on the specific paragraph, three different prices were evaluated for the carbon credits - a carbon credit equals a ton of $\mathrm{CO}_{2}$ avoided - during the definition of the business plan. In the first scenario, the actual price (5.00€/ton) was considered with consequent earnings of $750,000 €$ per year, and a payback period equals to 9 years. The second scenario assessed the price projection for 2020 which is supposed to be $20.00 € /$ ton. The resulting yearly profit would be around $3 \mathrm{M} €$; a result significantly higher than the actual scenario which could permit to reduce the payback period until 2 or 3 years. The lowest payback period, which turns out to be less than one year, has been obtained on the last analysis in which the carbon credit's price has been raised up to 50.00 $€ /$ ton according to the estimation for 2030. In conclusion, considering the market tendencies investigated during the COP21 in Paris, the intervention is sustainable from an environmental point of view as well as economic one.

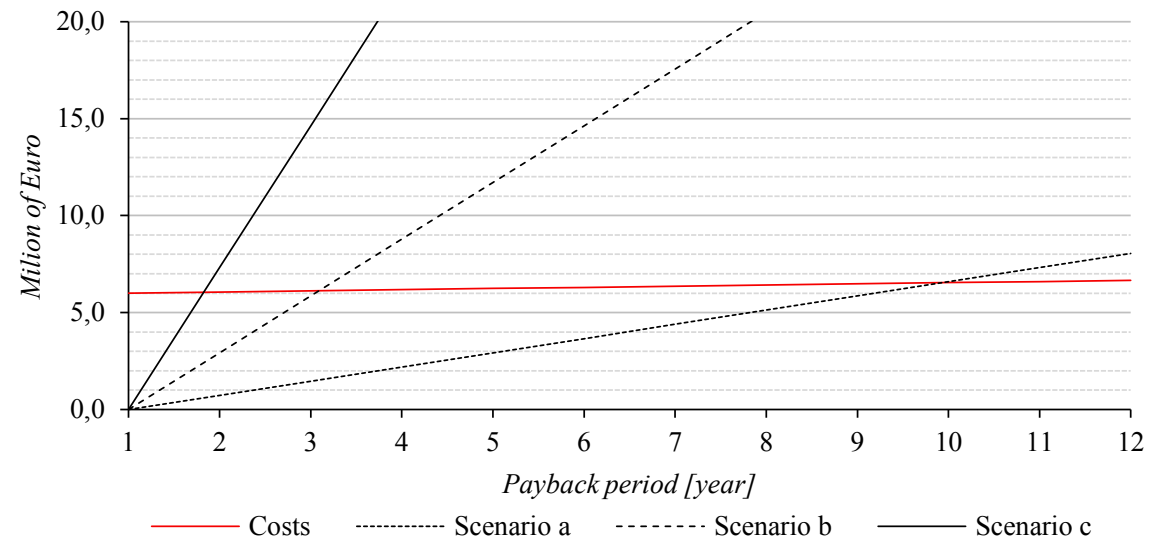

Table 1. Cost analyses and evaluation of the payback period.

\begin{tabular}{llll}
\hline Scenario & Carbon Credit cost $\left[€ / \mathrm{tCO}_{2 \text {-eq }}\right]$ & Earnings [M $€$ per year] & Payback period [year] \\
\hline Case $A$ - actual & 5.00 & 0.75 & $9-10$ \\
Case B - 2020 & 20.00 & 3.00 & $2-3$ \\
Case $C-2030$ & 50.00 & 7.50 & $<1$
\end{tabular}

Fig. 2. Payback period's calculation considering the scenarios a ( $5 € /$ ton $), b(20 € /$ ton $)$, and $\mathrm{c}(50 € /$ ton $)$. The intersections between the cost's line and the others represent the three payback period's values estimated. 


\section{Conclusions}

The present work demonstrates how alternative development strategies based on carbon credits as the high reflective shading system for shelters, could be advantageous not only from an environmental point of view but also in economic terms. According to the market tendency described by the French experts, the ETS could represent an adequate tool to be introduced on development strategies of countries which are rich in renewable energy sources or just able to produce a high amount of carbon credits. Thus, the workflow here proposed is a possible best practice which could be followed for planning in contexts and areas economically poor by attracting private funds in alternative ways. In fact, companies characterized by a high level of pollutant released are forced to compensate their emissions by investing on Renewable Energy Sources (RES) or buying carbon credits. On equal costs, an investor ethically oriented would probably prefer the second option for guaranteeing an enhancement of the life conditions of people living in the poorest areas (direct effect) as well as the rest of the Earth's population (indirect effect). In conclusion, the proposed technology has been demonstrated being replicable, feasible, and sustainable. Thus, it could be further tested on different contexts or at different scale by varying buildings' typology and evaluating the impact in terms of avoided carbon emissions.

\section{References}

[1] Barolini, Andrea. "The refugee camp of Zaatari. Where 80 thousand Syrians dream about coming back home." (2016) Available on-line at: https://www.lifegate.it/persone/news/campo-profughi-zaatari-siriani (last access $20^{\text {th }}$ October 2017).

[2] Ragnacci, Flavia and Bianconi, Fabio, “Albedo for Zaatari, Albedo and requalification of Zaatari refugee camp", Master thesis report submitted in December 2017. Department of Civil and Environmental Engineering, Perugia, Unpublished results.

[3] United Nations, Department of Economic and Social Affairs, Population Division (2014). World Urbanization Prospects: The 2014 Revision, Highlights (ST/ESA/SER.A/352)

[4] Oke, Timothy. "Canyon geometry and the nocturnal urban heat island: comparison of scale model and field observations." Journal of Climatology 1 (1981): 237-254.

[5] Musco, Francesco, and Fregolent, Laura. Urban planning and urban climate. Guidelines for Urban Heat Island mitigation, (2014) Padova, Il Poligrafo Editor.

[6] Shahmohamadi, P., Che-Ani, K., Maulud, K., Tawil, N., Abdullah, N. The impact of anthropogenetic heat on formation of urban heat island and energy consumption balance. (2011) London, Urban Studies Research.

[7] Akbari, H., and Kolokotsa, D. "Three decades of urban heat island and mitigation technologies research." Energy and Buildings 133 (2016): 833-842.

[8] Taha, H. "Urban climates and heat islands: albedo, evapotranspiration and anthropogenic heat." Energy and Buildings 25 (1997): 99-103.

[9] New York City Department of Design and Construction. High performance infrastructure guidelines, (2005) New York.

[10] City of Philadelphia. Philadelphia high performance building renovation guidelines, (2004) Philadelphia.

[11] Cotana, F., Rossi, F., Filipponi, M., Coccia, V., Pisello, A.L., Bonamente, E., Petrozzi, A., and Cavalaglio, G. "Albedo control as an effective strategy to tackle Global Warming: A case study." Applied Energy 130 (2014): 641-647.

[12] Cotana, F., Rossi, F., Filipponi, M., Coccia, V., Pisello, A.L., Bonamente, E., Petrozzi, A., and Cavalaglio, G. "Albedo control as an effective strategy to tackle Global Warming: A case study." Advances in Building Energy Research 7(2) (2014): 254-268.

[13] Bonamente, E., Rossi, F., Coccia, V., Pisello, A.L., Nicolini, A., Castellani, B., Cotana, F., Filipponi, M., Morini, E., and Santamouris, M. "An energy-balanced analytic model for urban heat canyons: comparison with experimental data." Advances in Building Energy Research 7(2) (2013): 222-234

[14] Rossi F., Cotana F., Filipponi M., Nicolini A., Menon S., and Rosenfeld A. "Cool roofs as a strategy to tackle global warming: economical and technical opportunities." Advances in Building Energy Research 7(2) (2013) doi: 10.1080/17512549.2013.865555

[15] European Climate Change Policy Beyond 2012 - World Energy Council 2009. Annex E: Alternative Technologies - Annex E1: Albedo Control System (ACS), (2009): 112.

[16] Rossi, F., Pisello, A.L., Nicolini, A., Filipponi, M., and Palombo, M. "Analysis of retro-reflective surfaces for urban heat island mitigation: A new analytical model." Applied Energy 114 (2014): 621-631.

[17] Rossi, F., Castellani, B., Presciutti, A., Morini E., Filipponi M., Nicolini, A., and Santamouris M. "Retroreflective façades for urban heat island mitigation: Experimental investigation and energy evaluations." Applied Energy 145 (2015): 8-20.

[18] Rossi, F., Morini, E., Castellani, B., Nicolini, A., Bonamente, E., Anderini, E., Cotana, F. "Beneficial effects of retroreflective materials in urban canyons: Results from seasonal monitoring campaign." Journal of Physics: Conference Series 655 (1) (2015).

[19] Akbari, H., Cartalis, C., Kolokotsa, D., Muscio, A., Pisello, A.L., Rossi, F. Santamouris, M. , Synnefa, A, Wong, N.H. and Zinzi, M. "Local climate change and urban heat island mitigation techniques - The state of the art." Journal of Civil Engineering and Management 22 (1) (2016) 1-16.

[20] Rossi, F., Castellani, B., Presciutti, A., Morini, E., Anderini, E., Filipponi, M. and Nicolini, A. "Experimental evaluation of urban heat island mitigation potential of retro-reflective pavement in urban canyons." Energy and Buildings 126 (2016): 340-352. 
[21] United Nations, Kyoto Protocol to the United Nations Framework, Convention on Climate Change, (1998) Kyoto.

[22] European Parliament and the Council of the European Union. Directive 2003/87/EC (2003).

[23] Gestore Servizio Energetico. European Emission Trading System (EU ETS): Report. (2015) GSE S.p.A.

[24] Fédération Internationale de Football Association, "Carbon Management and Climate Protection at FIFA, Football for the Planet." (2016) Available on-line at: http://resources.fifa.com/mm/document/afsocial/environment/02/83/13/97/carbonmanagementandclimateprotectionatfifa_neutral.pdf. (last access $26^{\text {th }}$ February 2018).

[25] UNHCR - United Nations High Commissioner for Refugee. Handbook for emergencies, (2007) Third Edition. Ginevra.

[26] UNHCR - United Nations High Commissioner for Refugee. Site planning and shelter. Camp restructure: project report. Zaatari refugee camp, (2016) Ginevra.

[27] UNOSAT - United Nations Institute for Training and Research. Al Zaatari Refugee Camp: 4 years of Displacement. (2016) Ginevra.

[28] Akbari H., Menon S., and Rosenfeld A. "Global cooling: increasing world - wide urban albedos to offset CO2." Climatic Change 94 (3-4) (2009): 275-286.

[29] Akbari H., Matthews H. D., and Seto D. “The long-term effect of increasing the albedo of urban areas.” Environmental Research Letter 7 (2) (2012).

[30] UNSD. "Climate change statistic and indicator.! (2016) Available on-line at: https://unstats.un.org/unsd/environment/envpdf/Issue39.pdf (last access $25^{\text {th }}$ May 2018). 